\title{
Knowledge of iodine nutrition in the South African adult population
}

\author{
PL Jooste ${ }^{1, *}, \mathrm{~N}$ Upson $^{2}$ and KE Charlton ${ }^{2,3}$ \\ ${ }^{1}$ Nutritional Intervention Research Unit, Medical Research Council, PO Box 19070, Tygerberg 7505, Cape Town, \\ South Africa: ${ }^{2}$ Divison of Nutrition and Dietetics, School of Health and Rehabilitation Sciences, University of Cape \\ Town, Cape Town, South Africa: ${ }^{3}$ Chronic Diseases of Lifestyle Unit, Medical Research Council, Tygerberg, \\ Cape Town, South Africa
}

\section{Submitted 6 July 2004: Accepted 8 November 2004}

\begin{abstract}
Objectives: To determine the level of knowledge regarding iodine nutrition and its relationship with socio-economic status in the South African population.

Design: A cross-sectional population survey collecting questionnaire information on knowledge of iodine nutrition and sociodemographic variables in a multistage, stratified, cluster study sample, representative of the adult South African population. Setting: Home visits and personal interviews in the language of the respondent. Subjects: Data were collected from one adult in each of the selected 2164 households, and the participation rate was $98 \%$.

Results: Only $15.4 \%$ of respondents correctly identified iodised salt as the primary dietary source of iodine, $16.2 \%$ knew the thyroid gland needs iodine for its functioning, and a mere 3.9\% considered brain damage, and $0.8 \%$ considered cretinism, as the most important health consequence of iodine deficiency. Compared with respondents from high socio-economic households, respondents from low socio-economic households were considerably less informed about aspects of iodine nutrition covered in this study.

Conclusions: The knowledge level of iodine nutrition is low among South Africans, particularly among the low socio-economic groups. These data suggest that the international emphasis on brain damage resulting from iodine deficiency has not been conveyed successfully to the consumer level in this country.
\end{abstract}

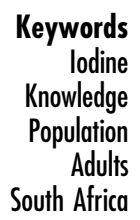

Given the public health importance of eliminating iodine deficiency, and the health consequences of its deficiency, it could theoretically be expected that consumers are informed and educated about iodine nutrition and iodinedeficiency disorders (IDD) such as impaired mental function, goitre, hypothyroidism, cretinism, retarded physical development and even child mortality. Despite widespread international efforts to implement effective IDD programmes, there is evidence from two studies in India that a very low level of public awareness exists regarding the role of iodine in the prevention of $\mathrm{IDD}^{1,2}$.

Furthermore, it has long been recognised that failure to inform and educate the public on IDD and how to address it is one of the reasons why many intervention programmes have been unsuccessful ${ }^{3,4}$. Low public awareness of IDD and lack of appreciation of the severity of the problem were also identified as constraints in control programmes at a conference held in the Harare in $1996^{5}$. An increased public awareness of the scope of the problem and solutions related to the prevention of IDD are key to empower consumers to increase demand for iodised salt. Evaluation of the level of knowledge about iodine nutrition in populations affected by iodine deficiency is essential to the optimal functioning and implementation of national iodisation programmes ${ }^{1}$.

Studies assessing public awareness of IDD and iodine nutrition in South Africa are limited. A study in six towns of the Northern Cape Province in South Africa showed that only $2 \%$ of mothers correctly knew the health benefit of iodine in iodised salt ${ }^{6}$. Another study, conducted before introduction of mandatory iodisation in the country, showed that despite the price of iodised and non-iodised salt being identical, a low proportion of low socioeconomic households (between 4.3 and 25\%) used iodised salt ${ }^{7}$. These data indirectly revealed the low level of awareness of the health benefit of iodised salt in the study area.

Two-and-a-half years following the introduction of mandatory iodisation of salt in South Africa in 1995, the proportion of households using iodised salt had increased to $86.4 \%$, and the proportion using adequately ( $>15 \mathrm{ppm}$ ) iodised salt was $62.4 \%{ }^{8}$. To sustain and further increase the use of iodised salt, the public needs to be appropriately informed and educated about the causes, consequences 
and prevention of iodine deficiency, in conjunction with periodic monitoring of the adherence of salt producers to iodisation legislation ${ }^{3}$. The current study was undertaken to assess the level of knowledge of the South African population regarding iodine nutrition and the consequences of iodine deficiency, and to relate IDD knowledge to socio-economic status.

\section{Methods}

A cross-sectional survey of the adult South African population was conducted by personal interview during home visits, to assess the knowledge of iodine nutrition in the country. Questionnaire data were collected by an experienced market research organisation as part of a regular countrywide household survey. The visiting points were drawn by means of a multistage, cluster, probability sample design of 2208 households, based on the 1996 South African national population census figures. The households and respondents were selected by listing all eligible respondents in a household and then using a random grid to choose the participating respondent. Only one respondent per selected household, aged 16 years or above, was included in the study. Substitution of the visiting point was allowed in the following cases: refusal, empty premises, nobody on the stand qualifying for the study, if the designated respondent could not be found after three visits, inability to communicate due to foreign home languages, or due to physical or mental limitations.

The study sample was selected proportional to the population size in each of the nine provinces, stratified according to nine residential categories representing the full range of types of residential categories existing in the country. These residential areas included traditional tribal rural areas and, in both metropolitan and non-metropolitan areas, informal settlements, hostels, townships, towns and cities. Exceptions to proportional sampling were required to achieve a predetermined minimum of 100 households per province and a minimum of 100 Asian households in order to generate sufficiently stable estimates for the provincial and overall national study sample. Census enumerator areas $(n=295)$ were used to form clusters, with either eight or four respondents drawn per enumerator area. The census enumerator area is the smallest geographical demarcation for census purposes and usually includes 150 to 200 households. All clusters were drawn with probability proportional to size, while respondents were drawn from the final enumerator areas with equal probability.

Fieldworkers collected the data by means of a structured questionnaire during March and April 2002. Information was obtained on sociodemographic characteristics of the respondent. To assess the knowledge of respondents concerning iodine nutrition, respondents were asked three questions, each eliciting a single response. These questions were: (1) 'What is the main source of dietary iodine of South Africans?' (2) 'Which part of the body (which gland in the body) needs iodine to produce hormones?' and (3) 'What is the most important harmful effect on the health of children if their iodine intake is insufficient?' Participants' responses were checked, without showing them the answer options, on a record sheet containing all possible responses determined during the piloting phases of the study.

Fieldworkers had at least 12 years of schooling and were bilingual or multilingual to be able to conduct the interview in the preferred language of the respondent. All fieldwork co-ordinators and fieldworkers were thoroughly trained and each was provided with a fieldworker's guide on how to conduct the interview and interpret responses. Co-ordinators checked at least 20\% of questionnaires for correct completion during the fieldwork, and the office contacted a further $15 \%$ of respondents to ensure that correct fieldwork procedures were followed during data collection (i.e. back-checks).

Approval for this study was obtained from the Ethics Committee of the University of Cape Town. In addition, it was explicitly stated at commencement of the interview that respondents were not obliged to answer any of the questions, that their participation was voluntary, and that all personal information would be confidential.

\section{Data analysis}

To correct for over-sampling, which was introduced to generate stable estimates, provincial and national data were adjusted in a weighted analysis using the 1996 census distributions to achieve representative population profiles. Summary statistics were generated, including frequencies, proportions and means. A multivariate index, which reflects socio-economic status on a 10-point scale, the Living Standards Measure (LSM), was calculated using 29 biographical variables obtained by questionnaire. Low LSM values indicated low socio-economic status and high values, high socio-economic status. Biographical data used for this purpose included the availability of household appliances (e.g. fridge, freezer, washing machine, tumble dryer, dishwasher, sewing machine, vacuum cleaner, microwave oven, electric stove, television, hi-fi, radio, cell phone, home computer, motor vehicle), household facilities (e.g. electricity, domestic servant, home security, piped water, hot running water, flush toilet), geographical area, and whether or not the respondent lived in a hut. This scale has been validated previously $^{9}$, and similar methodology was used in developing an LSM scale for Europe ${ }^{10}$. The LSM index was then graphically related to the percentage of respondents who identified iodised salt as the primary dietary source of iodine, and to the percentage of respondents who did not know what iodine is, and the significance of these associations determined by means of the Spearman correlation. 


\section{Results}

Overall, 2164 respondents, representing a national response rate of 98\%, participated in the study (Table 1). In terms of biographic data, the weighted study sample consisted of $74.7 \%$ black, 9.1\% coloured (mixed race) 2.9\% Asian and $13.3 \%$ white people, while $47.1 \%$ of the sample were male and $52.9 \%$ female, reflecting the ethnic and gender profiles of the country. The age distribution of respondents was $28.1 \%$ in the 16 to 24 years category, $25.2 \%$ aged 25 to 34 years, $18.5 \%$ aged 35 to 44 years, $11.4 \%$ aged 45 to 54 years, and $16.9 \%$ were 55 years and older. Between 6.0 and $16.1 \%$ of respondents belonged to the 10 different LSM categories, while 35.0\% fell in the lowest three LSM categories, $46.4 \%$ in the middle four categories and $18.6 \%$ in the three highest categories.

The frequencies of respondents' answers to the iodinerelated questions are summarised in Table 2 . Fifteen per cent of people in the country, ranging from 3.1 to $24.9 \%$ in the various provinces, knew that iodised salt is the most important or main source of iodine in the diet of South Africans. Lower percentages, between 4.9 and 5.8\%, of respondents believed that seafood, vegetables or meat was the most important dietary source of iodine. Only a few people considered dairy products, drinking water or other sources to be the primary source of iodine. Moreover, $65.7 \%$ of respondents were unable to answer the question, $43.2 \%$ of whom did not know what iodine is.

When asked which part of the body ('gland in the body') needs iodine to produce hormones, $16.2 \%$ of respondents correctly identified the thyroid gland (Table 2), while 5.7\% gave an incorrect answer. The remaining 78.1\% of respondents replied either that they did not know or they did not know what iodine is.

Respondents' perceptions of the most important harmful effect of inadequate iodine intake on the health of children are also summarised in Table 2 . The data show that, nationally, $9.4 \%$ of respondents considered impaired growth as the most important health consequence of iodine deficiency, while 5.5\% considered goitre, 3.9\% considered brain damage and $0.8 \%$ considered cretinism as the most important consequence. Low percentages of respondents mentioned hypothyroidism, death or other consequences. About three-quarters, 75.2\% of

Table 1 Provincial and national sample sizes and response rates

\begin{tabular}{|c|c|c|c|c|c|c|c|c|c|c|}
\hline \multirow[b]{2}{*}{ Characteristic } & \multicolumn{9}{|c|}{ Province } & \multirow[b]{2}{*}{$\begin{array}{l}\text { National } \\
\text { sample }\end{array}$} \\
\hline & $\begin{array}{l}\text { Western } \\
\text { Cape }\end{array}$ & $\begin{array}{l}\text { Eastern } \\
\text { Cape }\end{array}$ & $\begin{array}{l}\text { Northern } \\
\text { Cape }\end{array}$ & $\begin{array}{l}\text { Free } \\
\text { State }\end{array}$ & KwaZulu-Natal & Mpuma-Langa & Limpopo & Gauteng & $\begin{array}{l}\text { North } \\
\text { West }\end{array}$ & \\
\hline $\begin{array}{l}\text { Enumerator } \\
\text { areas (number) }\end{array}$ & 35 & 35 & 17 & 25 & 52 & 22 & 21 & 59 & 29 & 295 \\
\hline Sample size & 264 & 240 & 125 & 176 & 383 & 167 & 166 & 436 & 207 & 2164 \\
\hline $\begin{array}{l}\text { Weighted } \\
\text { sample size }\end{array}$ & 230 & 307 & 46 & 147 & 435 & 144 & 226 & 450 & 180 & 2164 \\
\hline $\begin{array}{r}\text { Response } \\
\text { rate (\%) }\end{array}$ & 100 & 96.8 & 100.8 & 100 & 95.8 & 97.1 & 101.2 & 96.5 & 99.5 & 98.0 \\
\hline
\end{tabular}

Table 2 Frequency (\%) of responses to iodine-related knowledge questions, by province and nationally

\begin{tabular}{|c|c|c|c|c|c|c|c|c|c|c|}
\hline \multirow[b]{2}{*}{$\begin{array}{l}\text { Responses to knowledge } \\
\text { questions }\end{array}$} & \multicolumn{9}{|c|}{ Province } & \multirow[b]{2}{*}{$\begin{array}{l}\text { National } \\
\text { sample }\end{array}$} \\
\hline & $\begin{array}{l}\text { Western } \\
\text { Cape }\end{array}$ & $\begin{array}{l}\text { Eastern } \\
\text { Cape }\end{array}$ & $\begin{array}{l}\text { Northern } \\
\text { Cape }\end{array}$ & $\begin{array}{l}\text { Free } \\
\text { State }\end{array}$ & KwaZulu-Natal & Mpuma-Langa & Limpopo & Gauteng & $\begin{array}{l}\text { North } \\
\text { West }\end{array}$ & \\
\hline \multicolumn{11}{|c|}{ Perceptions of the main dietary source of iodine } \\
\hline lodised salt & 18.2 & 15.4 & 3.1 & 24.9 & 16.7 & 20.7 & 6.1 & 17.1 & 6.5 & 15.4 \\
\hline Seafood & 11.1 & 3.6 & 6.0 & 5.4 & 2.6 & 5.0 & 2.5 & 11.6 & 1.0 & 5.8 \\
\hline Vegetables & 5.8 & 4.9 & 7.2 & 1.0 & 7.7 & 3.9 & 2.7 & 5.6 & 1.6 & 4.9 \\
\hline Meat & 3.0 & 2.4 & 3.1 & 0 & 8.8 & 3.2 & 8.3 & 5.9 & 2.4 & 5.0 \\
\hline Dairy products & 0.1 & 1.0 & 0.5 & 0 & 1.8 & 1.6 & 0 & 1.1 & 1.5 & 1.0 \\
\hline Other & 1.0 & 4.4 & 1.1 & 0 & 1.2 & 1.1 & 1.3 & 3.6 & 3.9 & 2.2 \\
\hline Do not know & 60.8 & 68.3 & 79.0 & 68.7 & 61.2 & 64.5 & 79.2 & 55.1 & 83.0 & 65.7 \\
\hline $\begin{array}{l}\text { Proportion knowing that the } \\
\text { thyroid gland needs iodine }\end{array}$ & 21.8 & 7.4 & 11.4 & 22.5 & 21.7 & 9.4 & 6.3 & 24 & 5.1 & 16.2 \\
\hline \multicolumn{11}{|c|}{ Perceptions of the most important harmful effect of iodine deficiency } \\
\hline Impaired growth & 11.4 & 9.3 & 10.4 & 10.4 & 12.2 & 1.0 & 3.9 & 13.7 & 2.3 & 9.4 \\
\hline Goitre & 4.5 & 2.1 & 0.9 & 5.0 & 9.1 & 6.6 & 3.9 & 7.2 & 1.9 & 5.5 \\
\hline Brain damage & 2.8 & 3.2 & 2.7 & 5.4 & 2.9 & 2.5 & 0.6 & 8.5 & 1.9 & 3.9 \\
\hline Cretinism & 0.2 & 0 & 0 & 0 & 4.0 & 0 & 0 & 0 & 0.1 & 0.8 \\
\hline Hypothyroidism & 1.1 & 4.9 & 0 & 1.3 & 0.4 & 0.6 & 0.5 & 1.9 & 0.2 & 1.5 \\
\hline Death & 0.4 & 2.2 & 0 & 0 & 0.5 & 0.7 & 0.5 & 3.4 & 1.3 & 1.4 \\
\hline Other & 1.5 & 4.7 & 2.0 & 0 & 2.0 & 5.7 & 0.8 & 2.5 & 1.2 & 2.4 \\
\hline Do not know & 78.1 & 73.6 & 84.2 & 77.9 & 68.9 & 82.9 & 89.8 & 62.7 & 91.2 & 75.2 \\
\hline
\end{tabular}


respondents, either did not know any of the abnormalities resulting from iodine deficiency or did not know what iodine is. When the frequencies of correct responses to the three questions were ranked and totalled by province, Limpopo and North West provinces had the lowest scores, reflecting the lowest levels of iodine nutrition knowledge.

Figure 1 illustrates the relationship between increasing LSM scores (i.e. higher socio-economic status) and the percentage of respondents who correctly identified iodised salt as the main source of dietary iodine ( $r=0.95, P<0.01$ ). Only $2.3 \%$ of subjects in the lowest LSM category, representing the lowest socio-economic group in the population, knew that iodised salt is the main source of dietary iodine, compared with $38.7 \%$ in the highest LSM category. A substantial proportion of all respondents, $43.2 \%$, did not know what iodine is. Figure 2 shows that $78.6 \%$ of people in the lowest LSM category did not know what iodine is, and that this percentage decreased with increasing LSM scores to $8.4 \%$ in people in the highest LSM category $(r=-0.98, P<0.01)$.

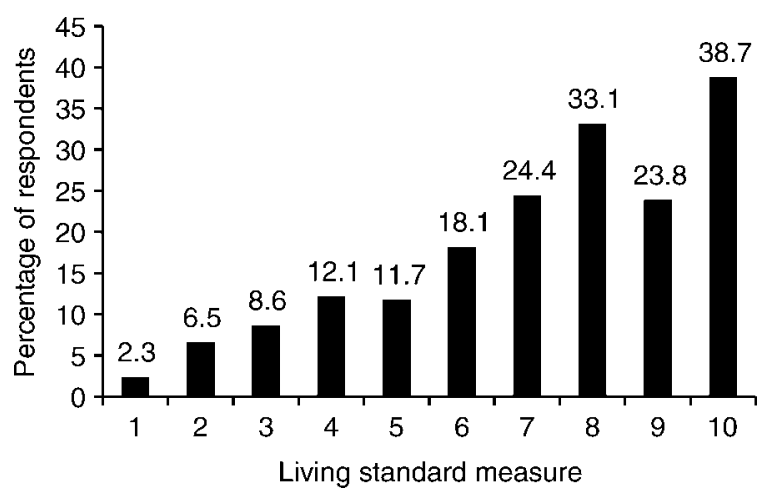

Fig. 1 Percentage of respondents identifying iodised salt as the primary dietary source of iodine in the various categories of the living standard measure as a composite index of socio-economic status, where 1 represents a low and 10 a high socio-economic status

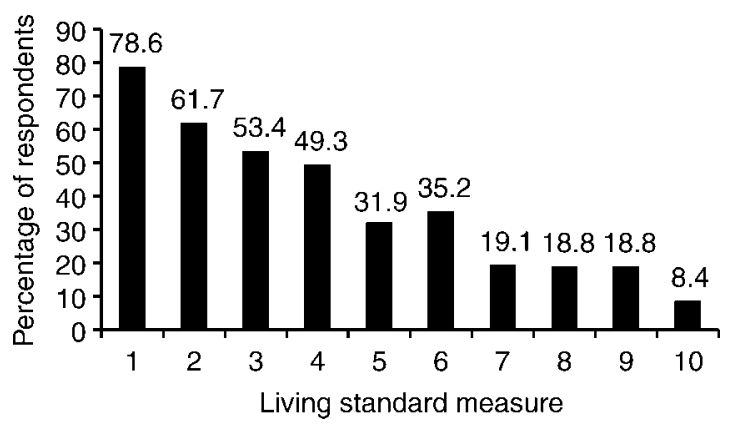

Fig. 2 Percentage of respondents who did not know what iodine is in the various categories of the living standard measure as a composite index of socio-economic status, where 1 represents a low and 10 a high socio-economic status

\section{Discussion}

Despite huge international efforts to eliminate IDD worldwide and remarkable progress towards this goal in many countries, it appears from limited information that these efforts have not resulted in a concomitant growth in knowledge regarding iodine nutrition. Data from the present national survey of IDD knowledge in South Africa have yielded similar information to studies from the Bargarh District ${ }^{1}$ and the Kashmir Valley ${ }^{11}$ of India and from the Andaman and Nicobar Islands ${ }^{2}$. In all these studies uniformly low levels of IDD awareness in the general public have been demonstrated. The discrepancy between progress in eliminating IDD and IDD knowledge of the population is particularly evident in South Africa, where we have shown that only $15.4 \%$ of people correctly identified iodised salt as the main source of dietary iodine, $16.2 \%$ knew which part of the body requires iodine for the production of hormones, and less than 5\% were aware of the neurological consequences of iodine deficiency. Even if 'seafood' is also accepted as a correct response to the question on the main source of dietary iodine, still $80 \%$ of the respondents were uninformed.

Against the background of the international emphasis on brain damage ${ }^{12}$, a surprisingly small percentage of respondents were aware that mental impairment might result from iodine deficiency. To close this IDD communication gap, which appears to inhibit the transfer of this message to the consumer level, both educational and public health communication strategies are required. In Turkey, the percentage of women using iodised salt increased significantly during a 3-month regional educational mass media campaign ${ }^{13}$, indicating that improved IDD knowledge may lead to a more widespread consumption of iodised salt.

Following the introduction of mandatory iodisation of table salt in South Africa at the end of 1995, at a higher iodine concentration than before, excellent progress has been reported on the iodine status of children ${ }^{14,15}$. However, indications of continued IDD in some areas of the country have been reported ${ }^{14}$ and a considerable proportion of households (37.6\%) was still using inadequately or non-iodised salt some 2.5 years following the revision of legislation ${ }^{8}$. Usually it is this last fraction of the population that is most difficult to reach with sufficiently iodised salt. While the impressive improvement in iodine status of the population in a relatively short period of time is undoubtedly attributable to the mandatory iodisation of salt, some other factors appear to have prevented the country from achieving the international goal of the virtual elimination of IDD.

Such factors have been shown to include under- or noniodisation $(<20 \mathrm{ppm})$ of about one-third of table salt at the production level, particularly in the case of coarse salt ${ }^{16}$, the use of non-iodised agricultural salt in 6.5\% of households, informal repackaging and selling of 
non-iodised salt for household use, and the vulnerability of low socio-economic subsets of the population to these shortcomings in the national salt iodisation programme ${ }^{8}$. It is important to note that a lack of IDD knowledge may well be a common denominator in all of these factors, further limiting progress in the salt iodisation programme. Therefore, overcoming the limiting factors mentioned above through increased IDD knowledge of the relevant role players, including the general public, may boost the chances of achieving and sustaining the elimination of IDD permanently.

These findings seem to suggest that while South Africa has indeed made good progress towards IDD elimination, as far as implementation of salt iodisation and coverage of iodised salt are concerned, the education and promotion aspects of the iodised salt intervention are seriously lacking. Reasons for the poor iodine nutrition knowledge might be inadequate inclusion of the topic in the school curriculum, little media reporting on the role of iodine in human health, the false notion that iodised salt will automatically solve the entire iodine deficiency problem, the fact that IDD is generally not a 'visible' condition, and the extensive public health focus on infectious diseases such as HIV/AIDS, tuberculosis and malaria. Against this background, it appears unlikely that the public will generate a demand for sufficiently iodised salt until their level of IDD knowledge has improved. In a situation like this, health authorities, together with the salt-producing industry itself, have an even greater social responsibility to ensure the effective implementation of salt iodisation.

It has previously been shown that low socio-economic groups in the South African population are the most vulnerable sector to exposure of insufficiently or noniodised household $\operatorname{salt}^{8}$. The present study has again underlined the vulnerability of these groups to iodine deficiency by demonstrating their particularly low level of awareness regarding the role of iodine nutrition, compared with people of higher socio-economic status. Strategies to strengthen the salt iodisation programme should target these groups, with the aim of improving knowledge about the prevention of IDD. An educational campaign of this nature would need to include a multipronged approach, whereby adequately iodised salt is widely marketed to poor communities as being superior to other sources of salt, and ensuring that the monitoring of the salt iodisation legislation takes place at points of sale in such communities.

In conclusion, this study has demonstrated that knowledge regarding iodine nutrition and the health consequences of iodine deficiency is unacceptably low in a representative sample of the South African population. Of particular concern is the finding that the international educational strategies to increase public awareness that iodine deficiency is a preventable cause of brain damage appear to have had very limited or no impact in the general population in South Africa. The lower level of knowledge about iodine nutrition in the lowest socioeconomic groups requires targeting of health education information about iodine nutrition.

\section{References}

1 Mohapatra SSS, Bulliyya G, Kerketta AS, Geddam JJB, Acharya AS. Elimination of iodine deficiency disorders by 2000 and its bearing on the people in a district of Orissa, India: a knowledge-attitude-practices study. Asia Pacific Journal of Clinical Nutrition 2001; 10: 58-62.

2 Mallik AK, Anand K, Pandav CS, Achar DP, Lobo J, Karmarkar MG, et al. Knowledge, beliefs and practices regarding iodine deficiency disorders among the tribals in Car Nicobar. Indian Journal of Pediatrics 1998; 65: 115-20.

3 Dunn JT. Seven deadly sins in confronting endemic iodine deficiency, and how to avoid them. Journal of Clinical Endocrinology and Metabolism 1996; 81: 1332-5.

4 Haxton DP. From knowledge to policy to practice. In: Hetzel BS, Pandav CS, eds. SOS for a Billion. The Conquest of Iodine Deficiency Disorders. New Delhi: Oxford University Press, 1996; 147-64.

5 Hasler J, Todd C, Mutamba J, Nyamandi T, Jumo D, Ropi F. Africa struggles for independence from IDD. IDD Newsletter 1997; 13: 17-27.

6 Jooste PL, Weight MJ, Kriek JA, Louw AJ. Endemic goitre in the absence of iodine deficiency in schoolchildren of the Northern Cape Province of South Africa. European Journal of Clinical Nutrition 1999; 53: 8-12.

7 Jooste PL, Weight MJ, Kriek JA. Iodine deficiency and endemic goitre in the Langkloof area of South Africa. South African Medical Journal 1997; 87: 1374-9.

8 Jooste PL, Weight MJ, Lombard CJ. Iodine concentration in household salt in South Africa. Bulletin of the World Health Organization 2001; 79: 534-40.

9 Haupt P. The South African Advertising Research Foundation universal Living Standards Measure $\left(S U-L S M^{\mathrm{TM}}\right)-12$ years of continuous development [online]. Available at www.saarf.co.za. Accessed 28 October 2004

10 Cír J. Consumer segments in Central and Eastern Europe. Research World 2004; 12: 18-9.

11 Zargar AH, Sofi FA, Masoodi SR, Laway BA, Shah NS, Wani AI, et al. Pattern of salt consumption and awareness about iodine deficiency disorders in Kashmir Valley. IDD Newsletter 1996; 12: 46-8.

12 World Health Organization (WHO)/United Nations Children's Fund/International Council for Control of Iodine Deficiency Disorders. Assessment of Iodine Deficiency Disorders and Monitoring their Elimination. WHO/NHD/01.1. Geneva: WHO, 2001.

13 Çan G, Ökten A, Green J. The role of local mass media in promoting the consumption of iodized table salt. Health Education Research 2001; 16: 603-7.

14 Immelman R, Towindo T, Kalk WJ, Paiker J, Makuraj S, Naicker J, et al. Report of the South African Institute for Medical Research on Iodine Deficiency Disorder Survey of Primary School Learners for the Department of Health, South Africa. Pretoria: Department of Health and the South African Institute for Medical Research, 2000.

15 Jooste PL, Weight MJ, Lombard CJ. Short-term effectiveness of mandatory iodization of table salt, at an elevated iodine concentration, on the iodine and goitre status of schoolchildren with endemic goitre. American Journal of Clinical Nutrition 2000; 71: 75-80.

16 Jooste PL. Assessment of the iodine concentration in table salt at the production stage in South Africa. Bulletin of the World Health Organization 2003; 81: 517-21. 